\title{
Utilização de biorreator anaeróbio de membrana dinâmica no tratamento de esgoto doméstico para uso agrícola
}

\section{Use of anaerobic dynamic membrane biorreactor in the treatment of domestic wastewater for agricultural use}

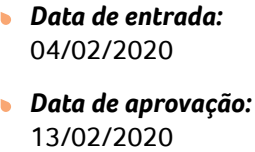

DOI: https://doi.org/10.36659/dae.2021.051

Juanne Nogueira Nascimento ${ }^{1 *}$ | Rafaela Barbosa Santos ${ }^{1}$ | José Raniery Rodrigues Cirne ${ }^{1}$ | Wilton Silva Lopes ${ }^{1}$ | José Tavares de Sousa ${ }^{1}$ | Valderi Duarte Leite' ${ }^{1}$ Marília Patrício Alves ${ }^{1}$

Lopes WS (iD https://orcid.org/0000-0002-0151-7664
Sousa JT (D) https://orcid.org/0000-0002-1056-1771
Leite VD (iD) https://orcid.org/0000-0001-5861-7407
Alves MP (iD https://orcid.org/0000-0001-8730-1145

Nascimento JN iD https://orcid.org/0000-0003-3036-2320

Santos RB (iD https://orcid.org/0000-0002-5512-5877

Cirne JRR (D) https://orcid.org/0000-0002-2879-9315

\section{Resumo}

Recentemente, a tecnologia dos Biorreatores Anaeróbios de Membrana Dinâmica tem sido uma abordagem adotada como uma alternativa promissora para resolver os problemas encontrados nos processos dos Biorreatores Anaeróbios de Membranas Convencionais, devido a fatores como baixo custo do módulo de membrana, menor custo de energia e um controle mais fácil de incrustação. Este estudo investigou o uso de um biorreator anaeróbio de membrana dinâmica para o tratamento de esgoto doméstico, avaliando o potencial de remoção de ovos de helmintos visando produzir um efluente para reúso agrícola. 0 sistema experimental foi operado na Estação Experimental de Tratamentos Biológicos de Esgoto Sanitário (Extrabes) em Campina Grande, Paraíba. A membrana dinâmica foi desenvolvida em um módulo de membrana externo sob uma malha de polietileno com tamanho médio de poro de $89 \mu \mathrm{m}$, e o reator foi operado sob um TDH de 8 horas. 0 sistema proporcionou um desempenho satisfatório, produzindo um efluente com turbidez média de 120,8 NTU, alcançando uma eficiência média de remoção de DQQO e ovos de helmintos de $56 \%$ e 94,4\%, respectivamente.

Palavras-chave: Biorreatores de Membrana. Membrana Dinâmica. Tratamento Anaeróbio. Esgoto Doméstico.

\section{Abstract}

Recently, Dynamic Membrane Anaerobic Bioreactor technology has been an approach taken as a promising alternative to solve the problems encountered in Conventional Membrane Anaerobic Bioreactor processes due to factors such as low membrane module cost, lower energy cost and easier fouling control. This study investigated the use of a dynamic membrane anaerobic bioreactor for the treatment of domestic wastewater, evaluating the potential for removal egg from helminths to produce an effluent for agricultural reuse. The experimental system was operated at the Experimental Station of Biological Treatments of Sanitary Sewage (Extrabes) in Campina Grande, Paraiba. The dynamic membrane was developed in an outer membrane module under a polyethylene mesh with an average pore size of $89 \mu \mathrm{m}$, and the reactor was operated under an 8 hour TDH. The system provided satisfactory performance,

\footnotetext{
${ }^{1}$ Universidade Estadual da Paraíba (UEPB) - Campina Grande - Paraíba - Brasil.

* Autora correspondente: juanne.nogueiraagmail.com.
} 
producing an average turbidity effluent of 120.8 NTU, achieving an average COD and helminth egg removal efficiency of $56 \%$ and $94.4 \%$, respectively.

Keywords: Membrane Bioreactors. Dynamic Membrane. Anaerobic Treatment. Domestic Wastewater.

\section{INTRODUÇÃO}

O tratamento de esgotos assume papel importante diante do uso desenfreado da água e da falta de investimento em saneamento básico, pois estes são os principais fatores que contribuem para degradação ambiental dos recursos hídricos e a disseminação de doenças de veiculação hídrica.

O Instituto Trata Brasil aponta que $64,2 \%$ da população paraibana não tem os seus esgotos tratados. Essa ausência de saneamento adequado tem impactos negativos significativos à saúde da população, como revelam os dados estatísticos do Ranking ABES da universalização, no qual se constatou que 6,5 mil pessoas residentes em municípios paraibanos foram internadas em 2017 em decorrências de problemas de saneamento ambiental inadequado. Em Campina Grande, 13 pessoas vieram a óbito por doenças de veiculação hídrica (DATASUS, 2017).

Diante dessa realidade se faz importante pesquisar práticas que ajudem a contribuir para a diminuição dos problemas resultantes da escassez, má distribuição e má qualidade da água. Uma prática que vem sendo difundida no mundo inteiro é o reúso de águas, utilizadas para diversos fins. A água de reúso, obtida a partir de esgotos tratados, utilizada na irrigação pode suprir as necessidades hídricas e proporcionar o fornecimento de nutrientes necessários das plantas (HERPIN et al., 2007).

Neste sentido, são imprescindíveis os investimentos no desenvolvimento de tecnologias de tratamento de esgotos alternativas, eficientes, de baixo custo e que garantam a qualidade dos efluentes. Entre as opções tecnológicas, o Bior- reator Anaeróbio de Membrana (BRAnM) surge como uma alternativa de tratamento de águas residuárias que possibilita a geração de água de reúso.

O BRAnM pode ser definido como um processo de tratamento biológico de águas residuárias que possui uma membrana filtrante para realizar a separação sólido - líquido de efluente tratado. A membrana garante a retenção dos microrganismos dentro do reator, propicia a geração de um efluente consistentemente de boa qualidade no que se refere ao teor de sólidos suspensos e turbidez, como também dependendo do tipo de membrana, contribui para a remoção de sólidos dissolvidos. Porém o custo das membranas convencionais (Micro/UltraFiltração), fenômenos de incrustação e baixo fluxo têm representado as principais desvantagens desse processo.

A tecnologia de Membrana Dinâmica (MD) tem sido recentemente proposta como uma alternativa ao uso das membranas convencionais, pois a filtração dinâmica tem menor risco de incrustação, requer menores custos de energia e de material de filtro, alcançando uma eficiência de tratamento equivalente aos BRAnMs (ERSAHIN et al., 2014). MD é uma camada de torta ou biofilme obtido por meio do deposito de material coloidal, substâncias poliméricas extracelulares (EPS), produtos microbianos solúveis (SMP) e sólidos suspensos (SS) sobre um material de suporte (ZHANG et al., 2010). São aplicados como material de suporte para formação da MD materiais mais baratos, como pano de filtro, malha de tecido e tecido não tecido, (SALEEM et al., 2016). Essa camada torna-se mais densa ao longo do tempo e tem capacidade de filtrar vários poluen- 
tes e patógenos. (SMITH et al., 2013; ERSAHIN et al., 2017). A membrana dinâmica pode ser facilmente removida da superfície do material de suporte e pode ser restabelecida novamente em curto espaço de tempo.

Outras principais vantagens da MD são a baixa resistência à filtração e a baixa pressão transmembrana (PTM). Todo o processo de filtração pode ser realizado sob gravidade, sem bombas. Essas características destacam o potencial da tecnologia da MD no tratamento de águas residuárias, a qual ainda requer inovação com relação ao tratamento eficiente e consumo de energia (Ll et al., 2018).

Os Biorreatores Anaeróbios de Membrana Dinâmica (BRAnMD) fornecem uma retenção completa de biomassa, permitindo o controle independentemente do tempo de detenção hidráulico (TDH) e do tempo de retenção de celular (TRC) (ERSAHIN et al., 2014). Nos sistemas de BRAnMs ocorrem TDHs relativamente mais curtos e longos TRCs, ou seja, a biomassa no biorreator é mantida mais tempo que o lodo, levando à redução do volume do biorreator, enquanto corresponde a altas taxas de digestão e melhora o desempenho do sistema (DAGNEW et al., 2012).

Geralmente, a operação do BRAnMD inclui três estágios: formação da camada da MD, filtração estável e limpeza para regeneração da MD (HU et al., 2017). $O$ controle adequado dos três estágios de filtração é crucial para alcançar um excelente desempenho do sistema, e esse controle ainda precisa ser mais investigado. Como exemplo, o tempo de formação da MD deve ser mais reduzido, o que minimizaria a produção de efluente com baixa qualidade no estágio inicial de filtração da $M D$, devido à rejeição insuficiente pelo próprio material de suporte. Além disso, a MD é sensível à turbulência hidráulica drástica, que pode influenciar a estabilidade da estrutura da MD e deve ser evitada durante a operação do biorreator (KISO et al., 2000). Assim, o desenvolvimento de uma camada de MD estável e altamente permeável é essencial para alcançar uma operação do BRAnMD estável e longa (YU et al., 2018).

Embora os BRAnMs tenham aplicação industrial em larga escala, a maioria dos estudos sobre MD são em escala de bancada no tratamento de águas residuárias sintéticas ou domésticas (ALIBARDI et al., 2016; HU et al., 2017).

Diante do exposto, o presente trabalho avaliou a eficiência de remoção de ovos de helmintos de um BRAnMD ao realizar o tratamento de esgoto doméstico, visando produzir um efluente para uso agrícola.

\section{OBJETIVOS}

\subsection{Objetivo Geral}

Estudar o processo de tratamento de esgoto doméstico em BRAnMD para produção de efluente dentro dos padrões desejáveis para uso agrícola.

\subsection{Objetivos específicos}

Otimizar os parâmetros operacionais do biorreator para maximizar a remoção de matéria orgânica;

Avaliar o desempenho do biorreator quanto à remoção de ovos de helmintos.

\section{METODOLOGIA}

\subsection{Modelo experimental}

Um Biorreator Anaeróbio de Membrana Dinâmica (AnDMBR) foi construído para realização do presente estudo e foi operado na Estação Experimental de Tratamentos Biológicos de Esgotos Sanitários (EXTRABES), situada na cidade de Campina Grande - Paraíba, local pertencente à UEPB. 
O esgoto doméstico tratado no sistema era gerado por um conjunto habitacional localizado a 200 metros de distância da estação, um condomínio familiar situado no bairro do Catolé constituído por 72 apartamentos e que fornecia uma vazão de 30 m3.d-1. 0 esgoto doméstico se direcionava para uma caixa de passagem, e a partir daí ocorria a distribuição desse esgoto para todas as pesquisas realizadas na Extrabes que faziam uso do mesmo. Com ajuda de um conjunto motor-bomba de fabricante KSB, $220 \mathrm{~V}$, modelo 50-160K, o esgoto era conduzido desse caixa de passagem para um tanque de equalização responsável pela alimentação diária do sistema.

O estudo foi realizado usando um BRAnMD, sistema composto por um digestor anaeróbio equipado com um módulo de membrana externo (Fig. 1), ambos construídos a partir de tubos e conexões de PVC. O sistema possuía uma capacidade volumétrica útil de $6 \mathrm{~L}$, e o digestor anaeróbio foi construído com altura total de 2 metros.

O módulo de membrana apresentava configuração externa de formato circular com diâmetro de $6,2 \mathrm{~cm}$. No seu interior encontrava-se uma malha de polietileno, com tamanho médio de poro de $89 \mu \mathrm{m}$, sendo utilizado como material de suporte para formação da membrana dinâmica. Esse valor médio de tamanho de poro foi calculado por meio de um programa de processamento de imagem baseado em Java e de domínio público, o Imagej. O interior do módulo de membrana e a malha de polipropileno utilizada como material de suporte são representados pela Fig. 2 .

O efluente alimentava o módulo de membrana por diferença de pressão hidráulica, e o permeado do módulo de membrana era coletado.

A pressão transmembrana foi medida por dois sensores de pressão MPX4250, que foram insta- lados antes do módulo de membrana e na linha do permeado. Uma placa micro controladora Arduino ATmega328 estava conectada aos sensores de pressão e equipada com um software que foi desenvolvido por Albuquerque (2017), o software SisMonBio, para controle e coleta de dados, permitindo assim que o sistema BRAnMD fosse acompanhado constantemente e que por meio desses dados fosse realizado o acompanhamento do desenvolvimento da membrana dinâmica. A interface do software está representada na Fig. 3. Os sensores reportavam os valores de pressão a cada 5 minutos, e ao fim do dia era realizada a média aritmética dos dados colhidos e assim obtido o valor da PTM diária. $O$ cálculo da PTM se dava por meio da Eq. 1:

PTM $=P_{e}-P_{s}$

Onde: $P_{e}=$ Pressão de entrada;

$P_{s}=$ Pressão de saída;

Inicialmente, para aclimatação do reator, foi utilizado um inóculo de lodo anaeróbio na proporção de 1:1, mistura que facilitou a adaptação da biomassa microbiana do sistema para receber o esgoto doméstico. O lodo anaeróbio foi obtido a partir de um reator UASB já em operação no laboratório (volume 25L, TDH de $12 \mathrm{~h}$ ). As principais características do inóculo estão descritas na Tabela 1.

Tabela 1- Principais características do inóculo utilizado

\begin{tabular}{|c|c|}
\hline Parâmetros & Valor \\
\hline $\mathrm{pH}$ & 7,17 \\
\hline $\mathrm{ST}\left(\mathrm{g} \cdot \mathrm{L}^{-1}\right)$ & 10,8 \\
\hline $\mathrm{STV}\left(\mathrm{g} \cdot \mathrm{L}^{-1}\right)$ & 4,25 \\
\hline $\mathrm{DQO}\left(\mathrm{g} \cdot \mathrm{L}^{-1}\right)$ & 2,8 \\
\hline Nitrogênio total $\left(\mathrm{mg} \cdot \mathrm{L}^{-1}\right)$ & 255 \\
\hline Fósforo total $\left(\mathrm{mg} \cdot \mathrm{L}^{-1}\right)$ & 74,2 \\
\hline
\end{tabular}




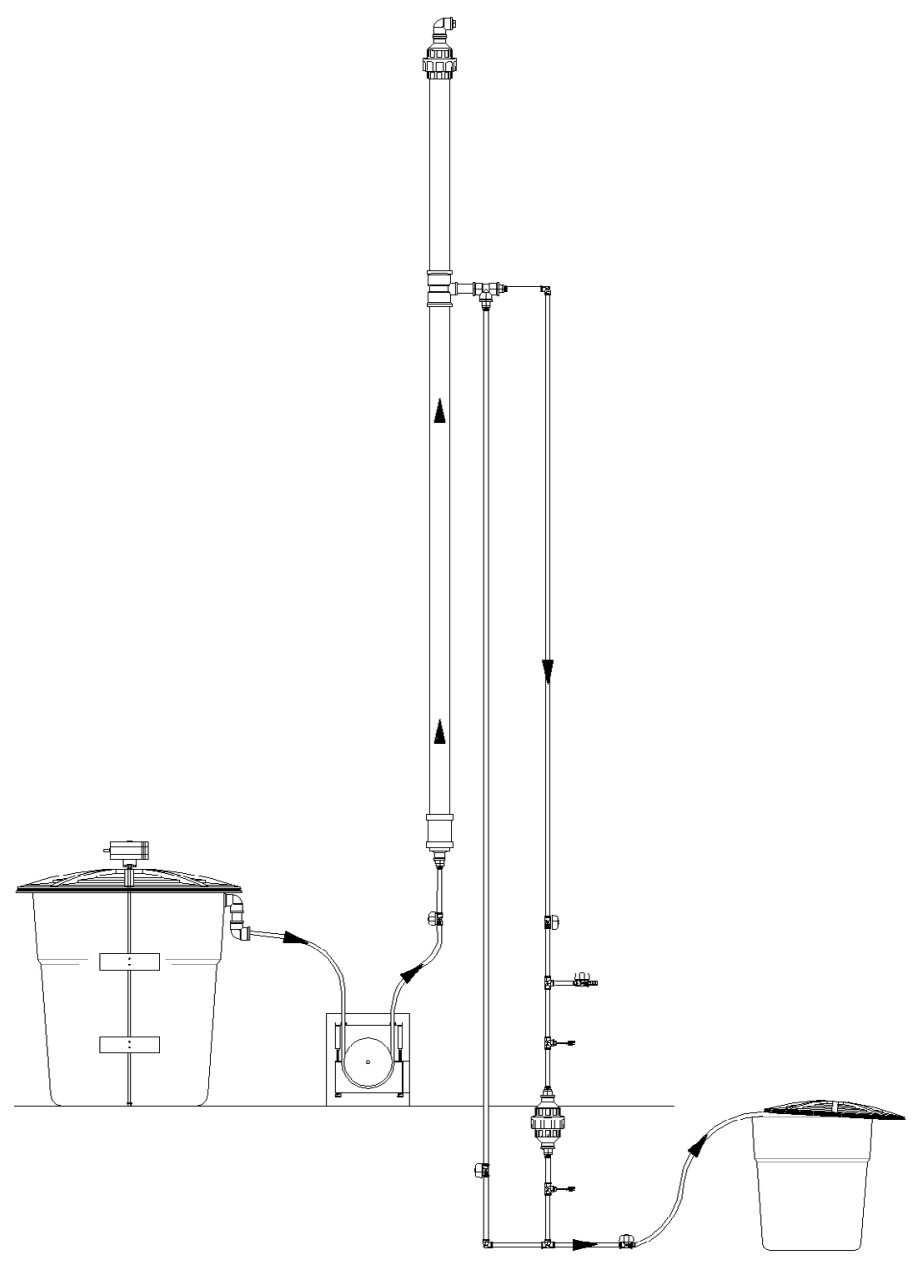

Figura 1- Esquema do sistema experimental que foi operado.

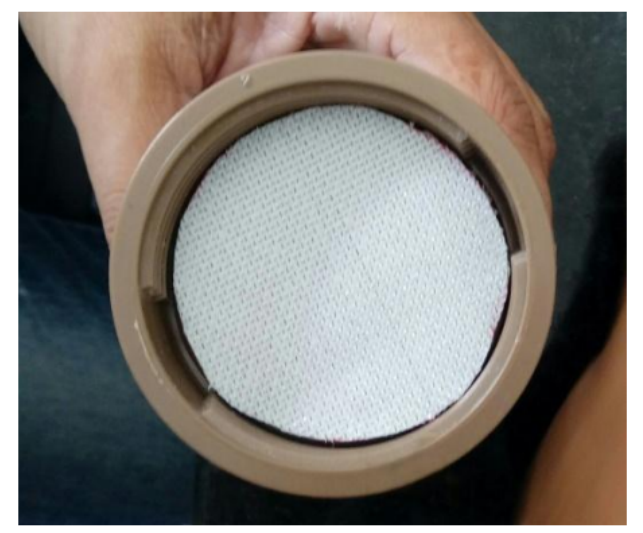

Figura 2- Interior do módulo de membrana e malha de polietileno. 


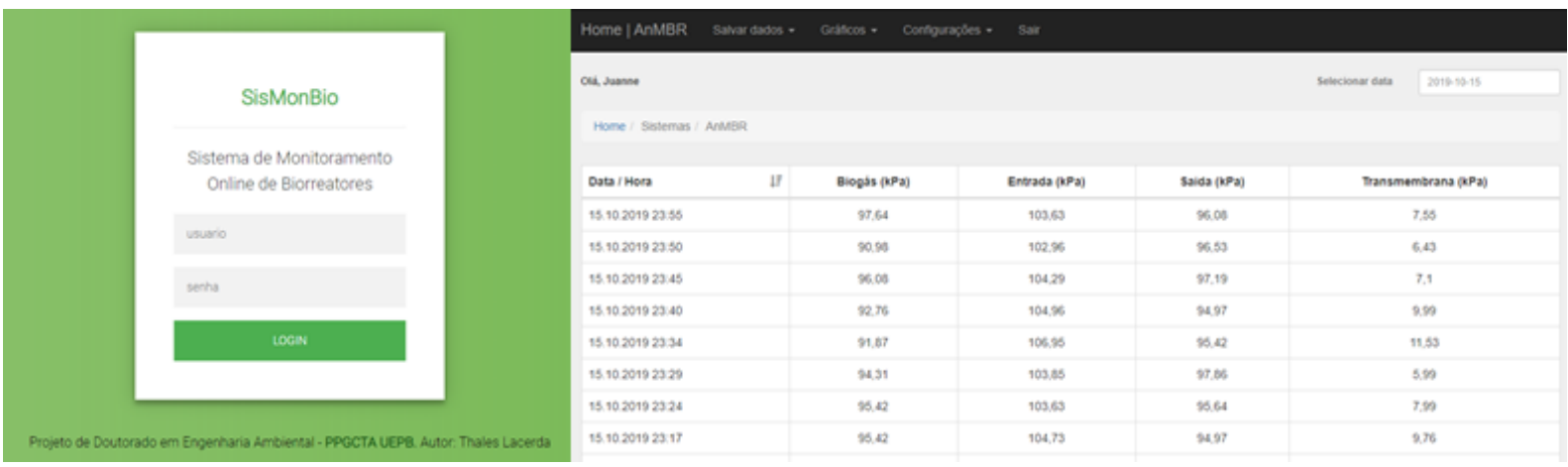

Figura 3- Interface do software SisMonBio

\subsection{Operação do Sistema}

O sistema BRAnMD foi operado por um período de 154 dias, entre o período de 30 de maio a 1 de novembro de 2019. O tempo de detenção hidráulica (TDH) adotado foi de 8 horas e um fluxo de $1500 \mathrm{~L}\left(\mathrm{~m}^{2} . h\right)$.

O esgoto doméstico tratado no sistema era armazenado em um tanque de equalização de 100 L homogeneizado por agitador mecânico por um período de 15 minutos em um intervalo de 30 minutos, para evitar sedimentação do mesmo. A alimentação do digestor anaeróbio era contínua de fluxo ascendente e fornecida por uma bomba peristáltica BP-200D (MS Tecnopon), a uma

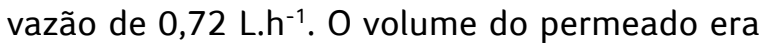
coletado em um balde instalado na saída do permeado no módulo de membrana.

O tempo de retenção de sólidos (TRS) foi adotado em 120 dias. Por definição operacional, não foi realizada retirada do lodo de excesso durante o período operacional.

Durante o período experimental foi realizada apenas uma retrolavagem na membrana dinâmica. A retrolavagem foi realizada com o próprio esgoto, fechando algumas válvulas do sistema e forçando o mesmo a passar pelo módulo de membrana com fluxo inverso ao de alimentação, realizando assim a limpeza do material de suporte e desmanchando a camada dinâmica já formada.

\subsection{Monitoramento da qualidade do afluente e do efluente}

As variáveis que estão sendo utilizadas para a caracterização do afluente e do efluente final, bem como as metodologias seguidas e as frequências de cada, são descritas na Tabela 2.

Tabela 2 - Metodologia e frequência utilizadas para análise dos parâmetros relacionados à eficiência do tratamento.

\begin{tabular}{|c|c|c|c|}
\hline Variáveis & Métodos & Referência & Frequência \\
\hline $\mathrm{pH}$ & Potenciométrico & Seção 4500 / APHA (2012) & Semanal \\
\hline DQQO Solúvel e Filtrada & $\begin{array}{c}\text { Titulométrico/ } \\
\text { Refluxação Fechada }\end{array}$ & 5220 C / APHA (2012) & Semanal \\
\hline Fósforo & Ácido ascórbico & Seção 4500 - P E/ APHA (2012) & Semanal \\
\hline Turbidez & Turbidímetro & (APHA, 2012) & Três vezes na semana \\
\hline Sólidos totais e suas franções & Método gravimétrico & 2540 E. / APHA (2012) & Quinzenal \\
\hline AGV & Kapp & BUCHAER et al (1999) & Semanal \\
\hline Alcalinidade & Titulação potenciométrica & 2320 B/APHA (2012) & Semanal \\
\hline Ovos de Helmintos & Bailenger & (WHO, 1989) modificado & Quinzenal \\
\hline
\end{tabular}




\section{RESULTADOS E DISCUSSÃO}

\subsection{Desempenho de filtração (PTM, Turbidez e Sólidos Totais)}

O perfil da PTM foi construído em função das médias dos meses de operação do BRAnMD, como observado na Fig. 4. Analisar a PTM é importante para acompanhar a formação e o desenvolvimento da membrana dinâmica, como também observar o comportamento de filtração realizado pela mesma.

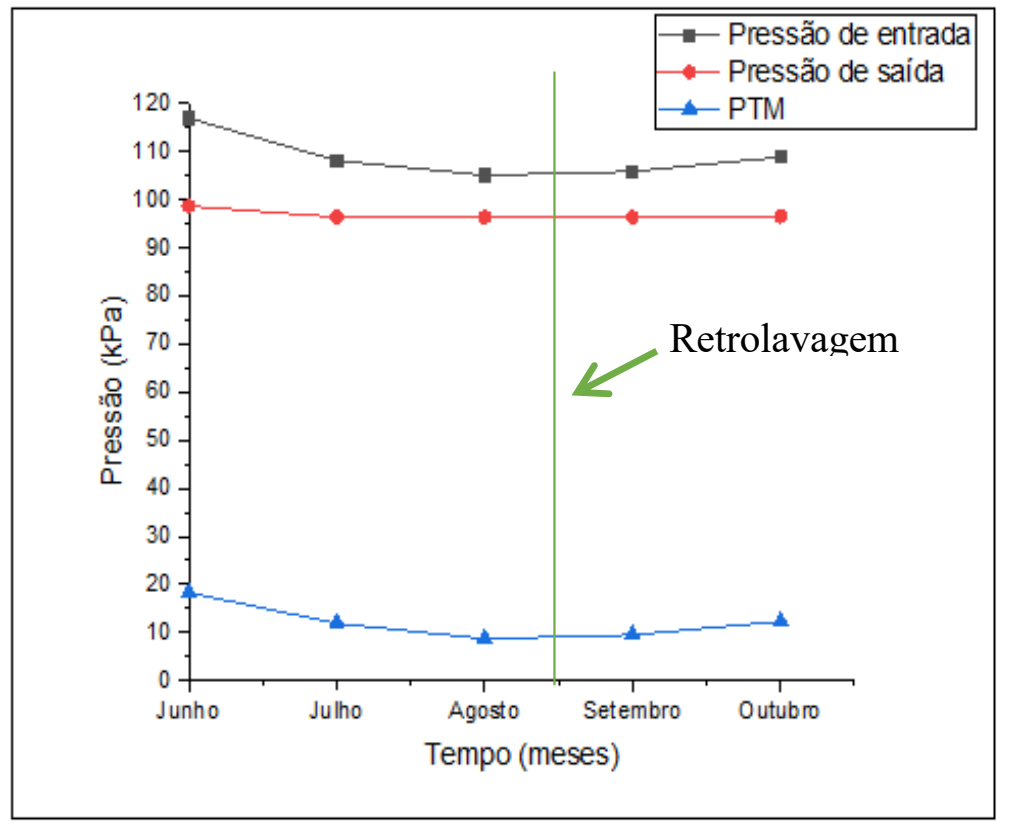

Figura 4 - Perfil de pressão transmembrana (PTM)

De acordo com a Fig. 4 é possível observar que a PTM se manteve baixa, entre a faixa de 8,7 e $18,3 \mathrm{kPa}$, durante todo o tempo de operação. É possível também verificar que houve uma acentuada queda na PTM logo após o primeiro mês de operação. A PTM foi afetada devido a uma falha na mangueira da bomba de alimentação, despressurizando a coluna d'água do biodigestor e ocasionando uma perturbação na membrana dinâmica. Depois do segundo mês foi realizada uma retrolavagem na membrana após ser observado registro do menor valor da PTM, e a membrana dinâmica foi totalmente desfeita para uma nova formação da mesma. Após a retrolavagem, é possível observar o aumento da PTM nos meses seguintes, indicando a formação e estabilidade da membrana dinâmica.
Na Fig. 5 observa-se o comportamento da turbidez do afluente e efluente produzido no BRAnMD durante os 154 dias de operação do sistema.

O sistema alcançou uma eficiência média de remoção de $60 \%$, atingindo uma turbidez média de $120,8 \pm 43,8$ NTU no efluente, o qual entrava inicialmente no biodigestor com uma turbidez média de 321,1 $\pm 127,3$ NTU. Hu et al. (2017), afirmam em seu estudo que a operação do BRAnMD inclui três estágios: formação da membrana dinâmica, filtração estável e retrolavagem da MD. No presente estudo foi possível identificar esses estágios de operação. Pode-se observar pela Fig. 5 que após a retrolavagem, realizada com 70 dias de operação, a eficiência de remoção de turbidez volta a aumentar, apesar da ocorrência de um 
comportamento de instabilidade, indicando um rápido início de formação da camada dinâmica, sendo esta mais conformada e estável a partir do $140^{\circ}$ de operação, quando apresenta crescente aumento de remoção, chegando a atingir uma eficiência de $69 \%$ do $154^{\circ}$ dia no efluente com turbidez de 79 NTU.

Levando em consideração o esquema proposto pelo projeto, conclui-se que se fazem necessários vários dias para estabilizar a membrana dinâmica na superfície do material de suporte. Li et al. (2018) afirmam que o fluxo crescente, con- centração afluente e tamanho do poro do material de suporte são fatores que podem auxiliar na redução dessa fase inicial de formação da membrana dinâmica.

Outro fator importante para caracterizar o efluente é a concentração de sólidos no reator. Esse parâmetro é imprescindível para compreender o mecanismo de formação da camada dinâmica sobre o material de suporte e acompanhar o seu desenvolvimento. Na Fig. 6 é possível observar as concentrações médias para as frações de sólidos totais para o afluente e o efluente.

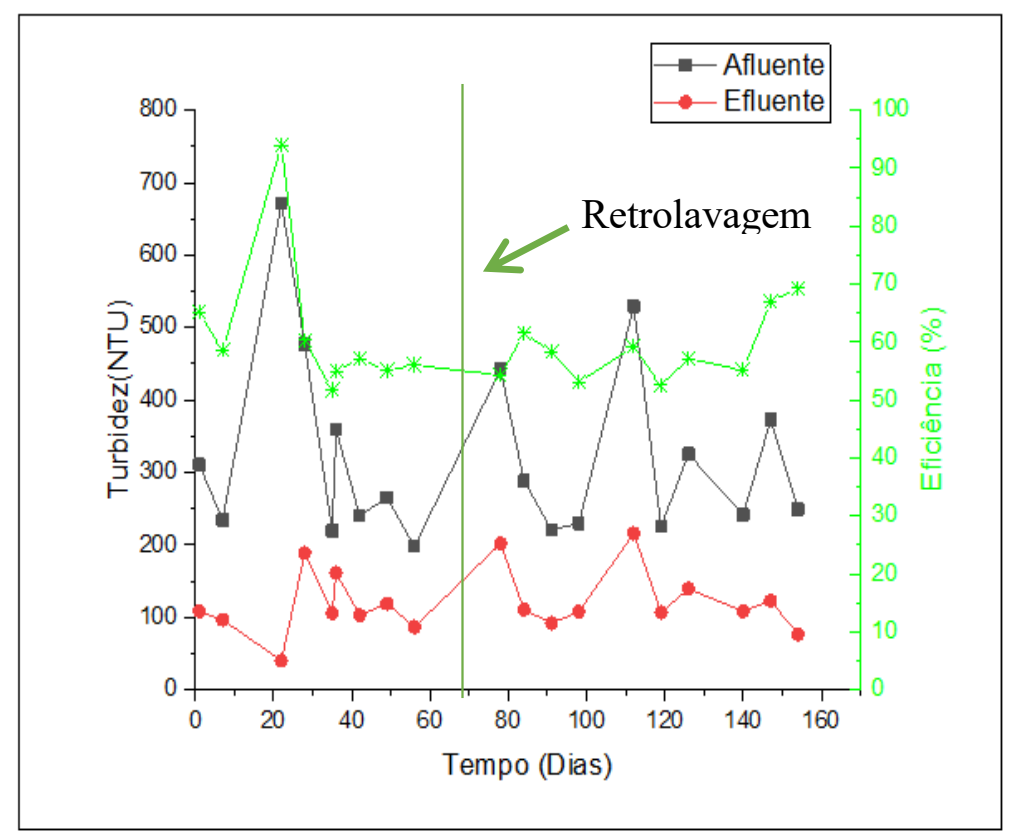

Figura 5 - Variação da turbidez no afluente e efluente e respectiva eficiência de remoção.

Os sólidos são fundamentais para a formação da membrana dinâmica, pois quanto maior a concentração de sólidos, mais rapidamente a camada de biofilme é formada. $O$ afluente apresentou concentração de 1,66 $\pm 0,65 \mathrm{~g} \mathrm{ST} . \mathrm{L}^{-1}$ e no efluente 0,91 \pm 0,28 g ST. $\mathrm{L}^{-1}$, alcançando uma eficiência de remoção de $43 \%$. Para o sólidos totais voláteis, o afluente apresentou uma concentração de $0,89 \pm 0,31 \mathrm{~g} \mathrm{STV} \cdot \mathrm{L}^{-1}$ e no efluente uma concentração de 0,49 $\pm 0,17 \mathrm{~g} \mathrm{STV.L^{-1 }}$, garantindo uma eficiência de remoção de 42,6\%. Podemos concluir que houve uma boa remoção dos sólidos presentes no reator, que provavelmente a maior parte de remoção foi da fração de sólidos suspensos, ajudando na formação da membrana dinâmica. Li et al. (2018) relataram que a concentração de sólidos suspensos aplicados no biorreator pode facilitar a formação da membrana dinâmica e reduzir a turbidez do efluente durante essa formação. 

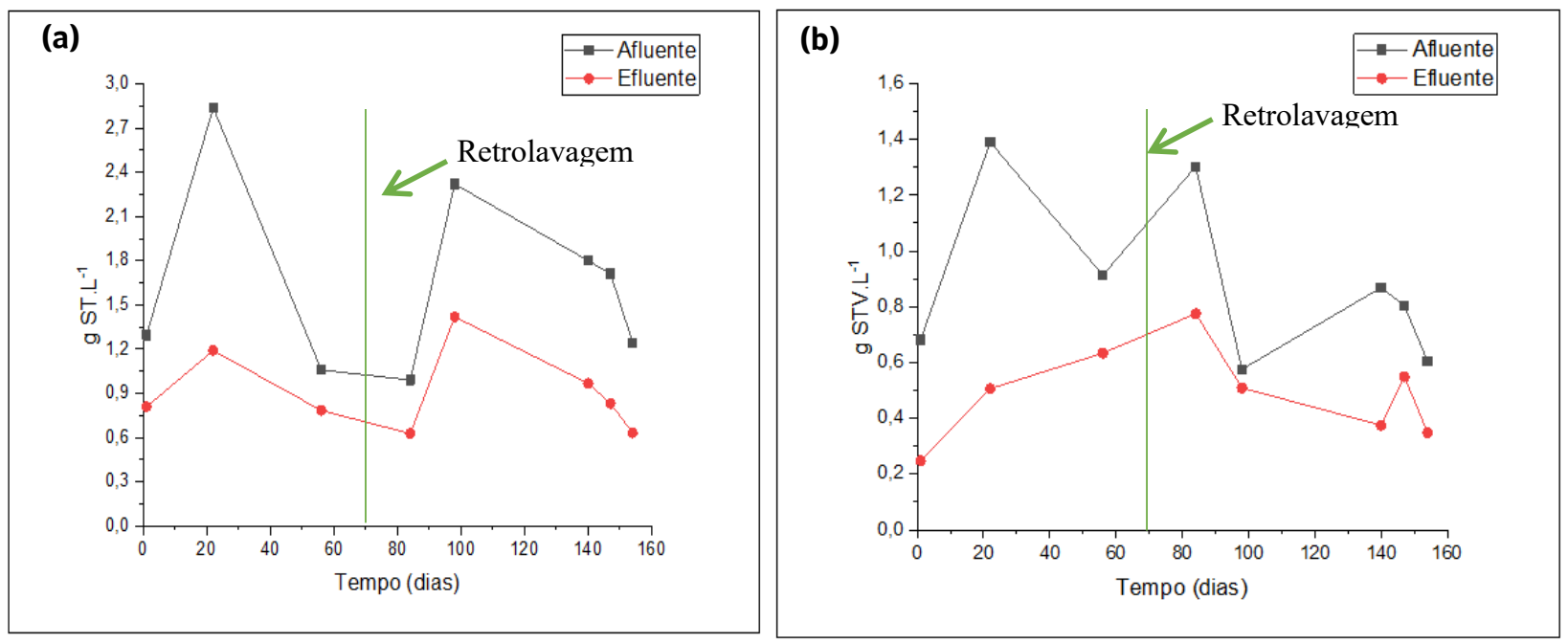

Figura 6 - (a) Valores médios de sólidos totais para afluente e efluente, (b) valores médios de sólidos totais voláteis para afluente e efluente.

\subsection{DQO e fósforo}

As concentrações de DQOH do afluente e efluente durante o período experimental em operação e sua eficiência de remoção no efluente são mostrados na Fig. 7. A filtração pela membrana dinâmica se mostrou eficiente na remoção de DQQO total. A eficiência média de remoção de DQQ foi de $56,01 \%$ com concentrações médias no afluente e efluente de 1,11 $\pm 0,5 \mathrm{~g} \mathrm{DQO} . \mathrm{L}^{-1} \mathrm{e}$ $0,47 \pm 0,2 \mathrm{~g} \mathrm{DOO} . \mathrm{L}^{-1}$, respectivamente.

Pela análise da Fig. 7, observou-se que a eficiência de remoção de DQOt apresentou a partir do $20^{\circ}$ dia de operação uma queda acentuada; foi então realizada uma retrolavagem na membrana com 70 dias de operação. Pôde-se verificar que com esse processo, a partir do $100^{\circ}$ dia, e que apesar da variação do afluente, o efluente se mostrou mais estável em relação à concentração de DOQOt, aumentando a sua eficiência de remoção de material orgânico, chegando a alcançar eficiência de $69 \%$ no $149^{\circ}$ dia.

O biorreator apresentou comportamento satisfatório em relação à remoção de DQO total quando comparado a outras literaturas, como também quando comparado à tecnologia UASB. Hirakawa et al. (2002), utilizando a tecnologia do reator UASB para tratar esgoto sanitário bruto, alcançaram uma eficiência média de remoção de DQOOt de $50 \%$.

Zhang et al. (2010) obtiveram uma eficiência de remoção de DQQ entre 57 e $63 \%$ utilizando o BRAnMD para tratar águas residuárias. Alibardi et al. (2016) operaram um biorreator de membrana dinâmica em escala de bancada para avaliar o tratamento anaeróbio de águas residuárias sintéticas e concluíram que, operando o sistema de tratamento com TRH menor que 0,5 d, a eficiência de remoção de DQQ foi entre 50\% e $60 \%$.

A Fig. 8 apresenta ao longo do tempo as variações das concentrações de DQQO solúvel do afluente e do efluente. A eficiência de remoção de DQQO solúvel foi mais baixa comparada à DQOt, ficando na média de $49 \%$. As concentrações médias de DQQO solúvel no afluente foram de 0,31 \pm $0,15 \mathrm{~g}$ DQO. $\mathrm{L}^{-1}$ e no efluente de 0,15 \pm 0,06 g DQO. $\mathrm{L}^{-1}$. A razão média DQO solúvel / DQQ total é de 0,32 no efluente; este resultado indica que a maior parte de DQO que sai junto ao efluente é particulado e não dissolvido. 


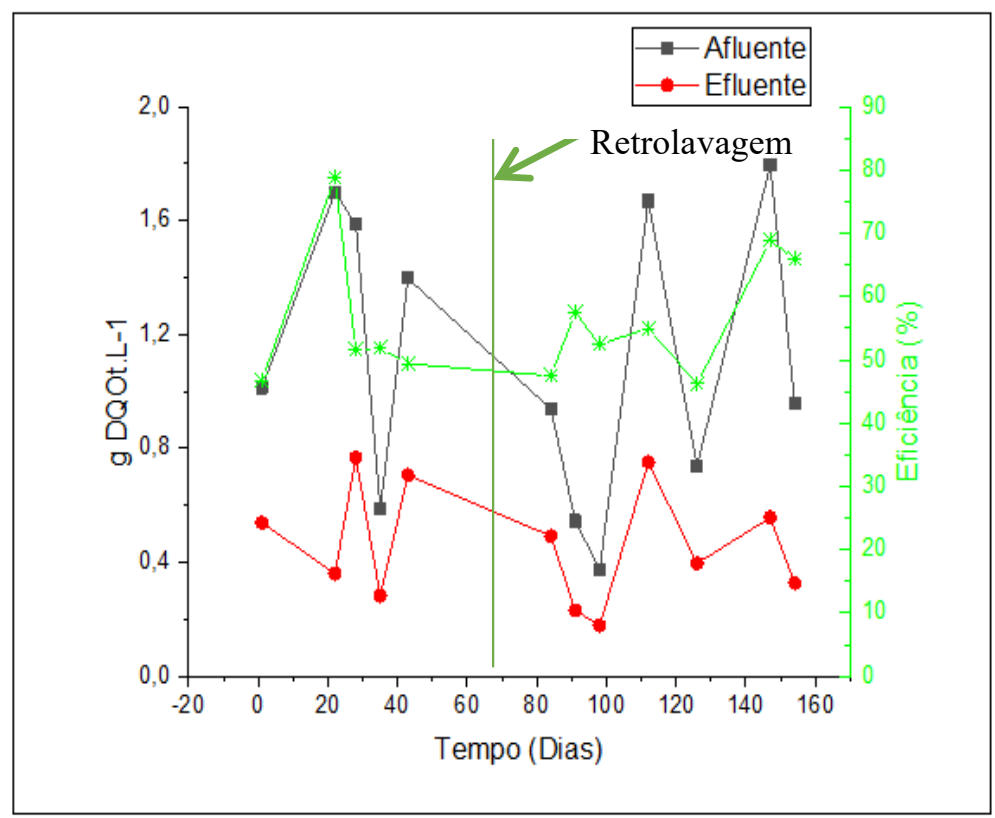

Figura 7 - Concentração da DQ̨O total e respectiva eficiência de remoção.

De acordo com os valores de remoção de DQQO total obtidos, percebe-se a necessidade de um período de aclimatação para que o sistema se desenvolva e acredita-se, portanto, que a continuação da operação do reator geraria um efluente de excelente qualidade. Ersahin et al. (2017) afirmaram que para obter uma camada de mem- brana dinâmica estável e eficaz, com configuração de módulo de membrana externa, que gere um permeado de alta qualidade, é necessário um maior tempo de operação. Eles obtiveram uma eficiência de remoção de DQO equivalente a 99\% mas somente após um período de aclimatação do BRAnMD superior a 200 dias.

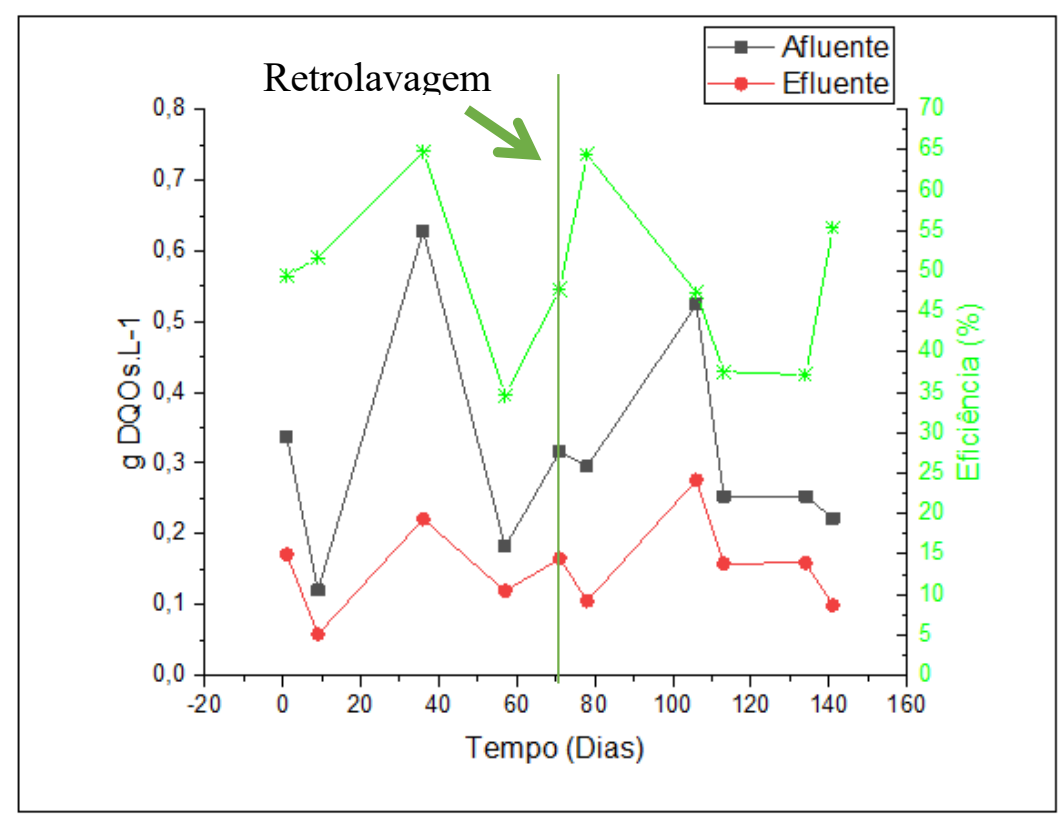

Figura 8 - Concentração da DQQO solúvel. 
Quanto ao desempenho de remoção de fósforo, apresentado na Fig. 9, o BRAnMD mostrou um bom desempenho em comparação com os resultados reportados em outras literaturas. A concentração média de fósforo para o afluente foi de $12,14 \pm 4,05 \mathrm{mg} \mathrm{P.L^{-1 }}$ e durante o experimento foi possível obter um efluente com uma concentração média de 7,72 \pm 3,35 mg P.L - $^{-1}$, implicando em uma eficiência de remoção de $37,4 \%$.
Em estudos realizados por Ersahin et al. (2014), tratando águas residuárias sintéticas em BRAnMD, a taxa de remoção de fósforo foi de $13 \%$. Nesses tipos de sistemas já é esperada a baixa eficiência de remoção de nutrientes, e a remoção acontece com o resultado do crescimento da membrana dinâmica, pois com a diminuição dos poros o material particulado fica retido na membrana. 0 resultado obtido pode ser vantajoso na utilização desse efluente para reúso agrícola.

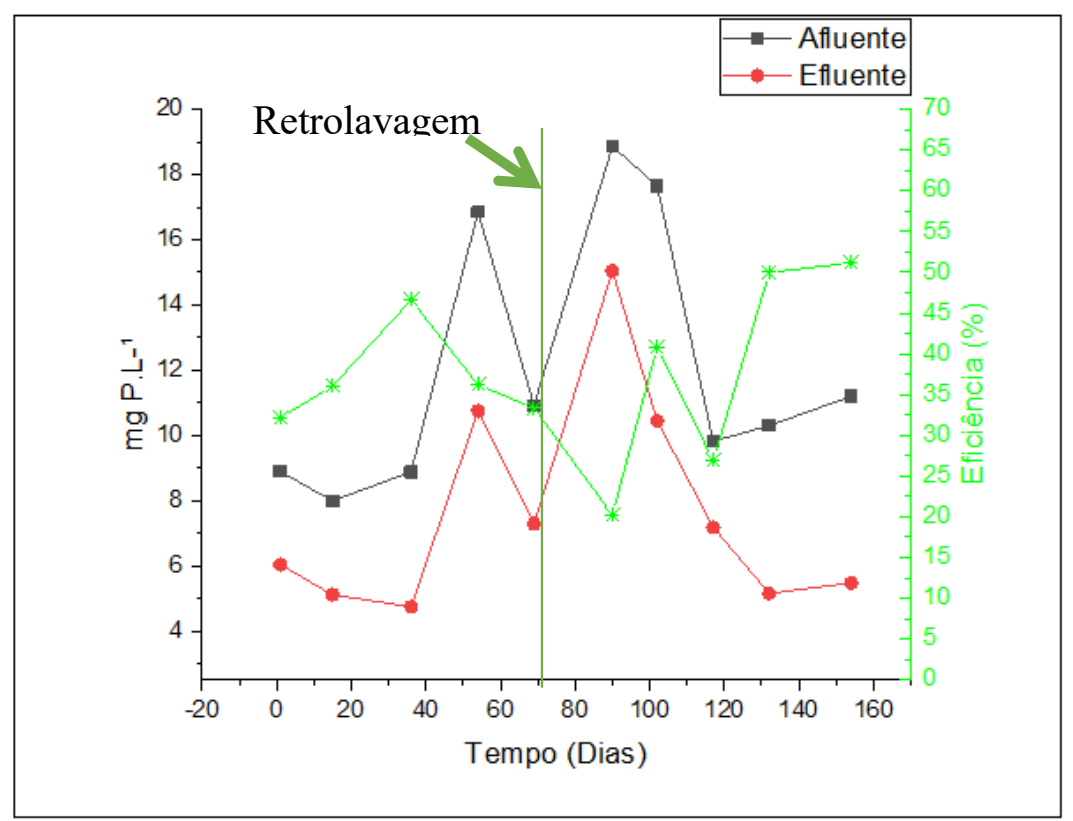

Figura 9 - Comportamento das concentrações de fósforo total.

\section{3 pH, AGV e Alcalinidade}

Os resultados das determinações físico-químicas de $\mathrm{pH}$, alcalinidade e AGV em termos de médias e desvios estão dispostos na Tabela 3.

Tabela 3 - Resultados das análises físico-químicas de $\mathrm{pH}$, alcalinidade e AGV.

\begin{tabular}{|c|c|c|}
\hline Parâmetro & Afluente & Efluente \\
\hline pH & 6,82 a 7,49 & 7,11 a 7,79 \\
\hline Alcalinidade & $369,26 \pm 113.6$ & $363,41 \pm 115,41$ \\
\hline AGV & $150,29 \pm 61,9$ & $82,6 \pm 44,12$ \\
\hline
\end{tabular}

Os parâmetros acidez, alcalinidade e pH são de extrema importância para a digestão anaeróbia. Os ácidos graxos voláteis devem estar em equilíbrio com a alcalinidade do sistema. $\mathrm{O} \mathrm{pH}$, como parâmetro de avaliação do sistema, é de utilidade para avaliar as condições de acidez e alcalinidade, pois a inibição do processo anaeróbio por ácidos graxos voláteis está associada ao $\mathrm{pH}$. Os ácidos graxos voláteis em sua forma não ionizada são tóxicos para as bactérias metanogênicas. A baixos valores de $\mathrm{pH}$, os ácidos graxos voláteis 
estão menos desassociados e, portanto, são tóxicos. Os valores de $\mathrm{pH}$ geralmente desejados em um tratamento anaeróbio estão entre 6,5 e 7,5, em que a maioria dos ácidos orgânicos estão em sua forma ionizada, como também é a faixa de $\mathrm{pH}$ ótimo para crescimento da grande maioria das bactérias (Campos et al., 2006).

A Fig. 10 apresenta a variação temporal do pH, AGV e alcalinidade. Dos valores apresentados, pôde-se observar que os valores de $\mathrm{pH}$ encontram-se na faixa adequada de $\mathrm{pH}$ para a digestão anaeróbia, que foram na média geométrica de 7,49 e 7,42 para o afluente e efluente, res- pectivamente, e que o mesmo manteve uma constância temporal durante toda a operação do sistema.

Ocorreu uma redução de $45 \%$ de ácidos graxos voláteis comparando-se o afluente com o efluente, como observado na Fig. 11. Demostrando assim que dentro da faixa de $\mathrm{pH}$, a qual operou o biorreator, os ácidos graxos voláteis estavam na sua grande maioria de forma ionizada, não tóxicos para às bactérias metanogênicas. A alcalinidade apresentou poder tamponante e em equilíbrio com os demais parâmetros; a variação da alcalinidade pode ser observada na Fig. 12.

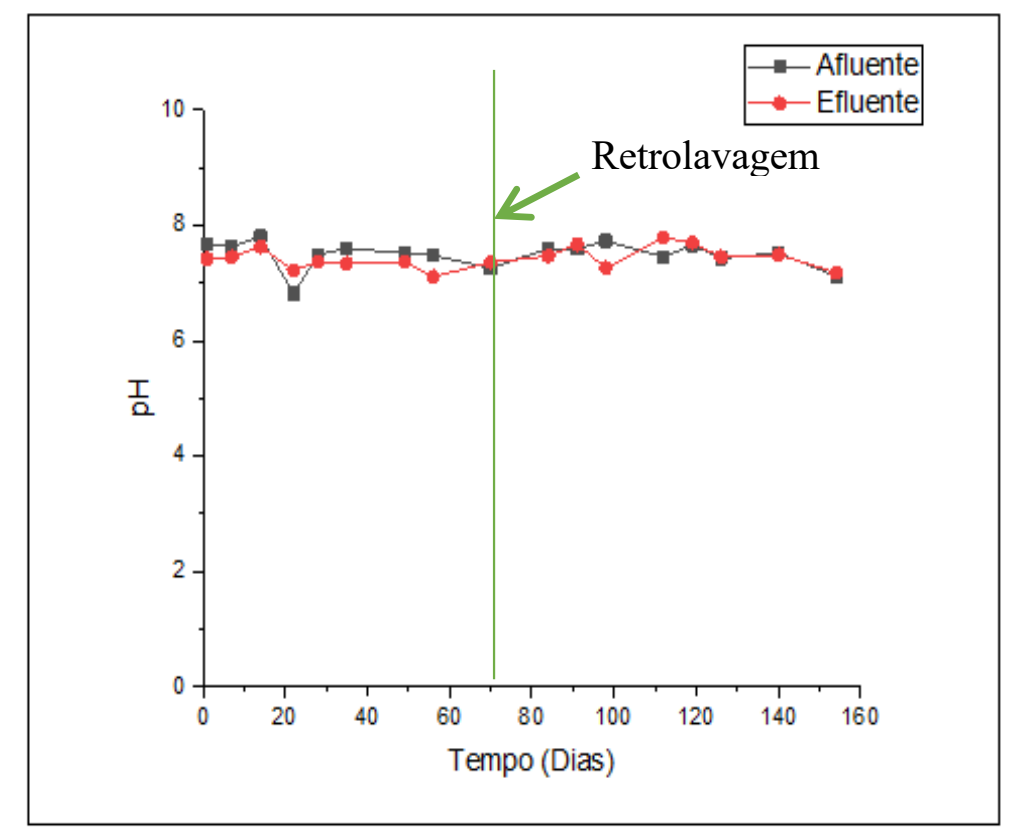

Figura 10 - Variação temporal do pH. 


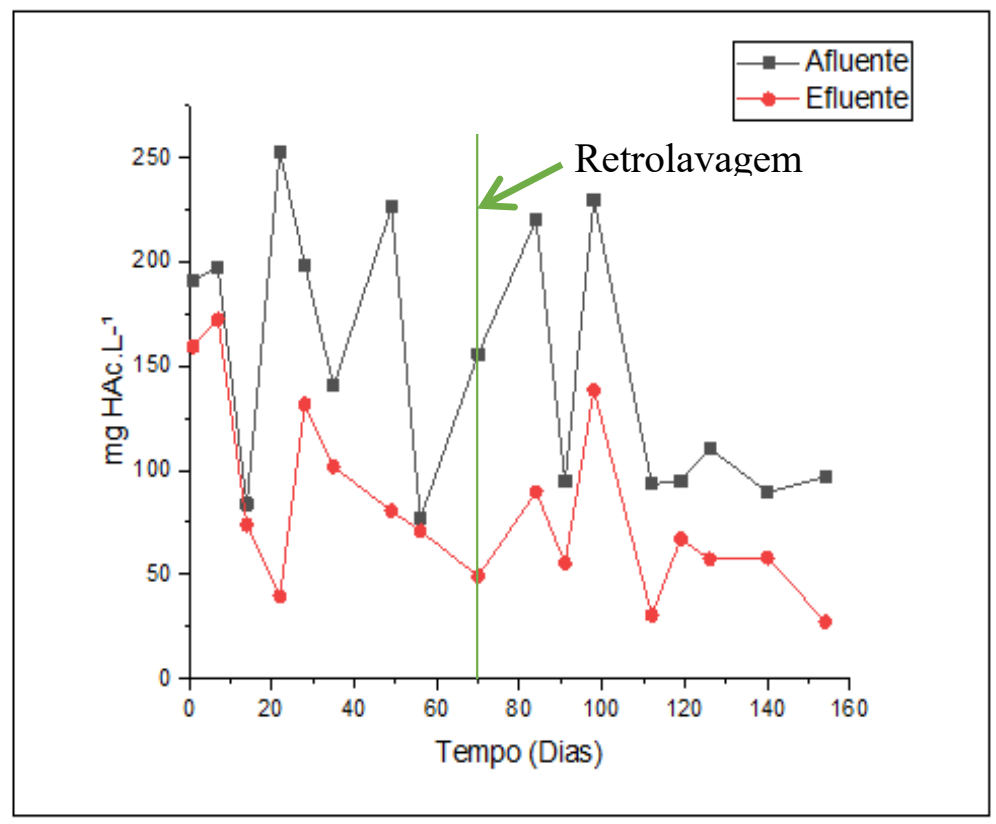

Figura 11 - Variação temporal de AGV



Figura 12 - Variação temporal da alcalinidade

\subsection{Ovos de helmintos}

$\mathrm{Na}$ Fig. 13 estão apresentados os resultados da variação dos números de ovos ao longo do tempo de operação encontrados no afluente e no efluente e sua eficiência de remoção no efluente. As concentrações médias de ovos de helmintos no afluente foram de $65,3 \pm 13,6$ ovos. $L^{-1}$ e no efluente de 3,5 $\pm 3,3$ ovos. $L^{-1}$. Os ovos que estão presentes nas águas residuárias ocorrem em função dos hábitos de higiene da população; vale lembrar que a água residuária doméstica utilizada neste trabalho é proveniente de um condomínio próximo ao laboratório, que está situado em um bairro nobre da cidade, o que explica a baixa 
concentração de ovos helmintos encontrada no afluente quando comparado a outras literaturas.

O sistema obteve uma eficiência de remoção de ovos de helmintos no efluente que foi de $94,4 \%$. Pode-se observar que, à medida emque a membrana dinâmica vai se tornando mais consolidada e estável ela, de fato, consegue realizar a remoção eficiente dos ovos no efluente, encontrando no último dia de operação uma concentração de 0,67 ovos.L-1. Verbyla et al. (2013) apresentaram uma eficiência de remoção de ovos de helmintos no efluente de apenas $23 \%$, avaliando a operação reator UASB na recuperação de águas residuárias.

No início do processo de filtração, o efluente apresenta concentração de ovos ainda elevada quando comparada aos padrões recomendados para reúso pela OMS, que é de $\leq 1$ ovo. $L^{-1}$. Porém, como dito anteriormente, ao longo do tempo a filtração vai se tornando mais estável e observa-se a redução das concentrações dos ovos no efluente, chegando a atingir a concentração recomendada pela OMS para uso do efluente em reúso agrícola.

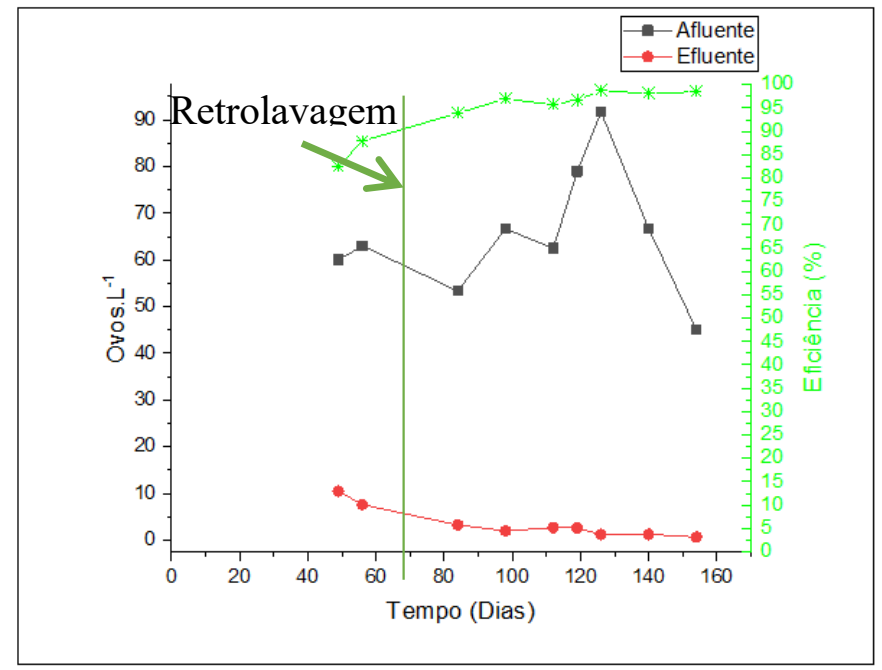

Figura 13 - Variação da concentração de ovos de helmintos no afluente e no efluente.

\section{CONCLUSÃO}

O biorreator anaeróbio de membrana dinâmica tratando esgoto doméstico, levando em consideração esquema operacional proposto visando à redução de gasto energético, teve desempenho satisfatório na remoção de ovos de helmintos, chegando a 94,4\% de eficiência. Observou-se que após estabilização e completa formação da membrana dinâmica o processo de filtração produz efluente viável para sua aplicação em reúso agrícola. Observou-se também boa remoção de
DQO e turbidez, alcançando eficiência média de $56 \%$ e $60 \%$, respectivamente.

Quanto à remoção de Fósforo total, a eficiência de remoção foi de 37,4\%. Uma boa eficiência foi alcançada quando comparada a outros trabalhados, porém para objetivo do trabalho de utilização do efluente na agricultura tal concentração de nutriente se torna benéfica. $O$ efluente apre-

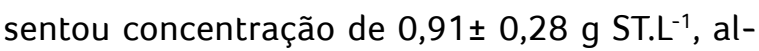
cançando uma eficiência de remoção de $43 \%$. As 
concentrações de sólidos do reator favorecem a formação da membrana dinâmica.

Durante a operação do sistema experimental foi possível verificar que o BRAnMD necessita de um período de aclimatação do reator, no qual ocorre a formação e a estabilização da membrana dinâmica, podendo assim alcançar resultados excelentes. Pode-se concluir que a tecnologia da MD pode proporcionar um ótimo desempenho de filtração produzindo um efluente com características promissoras. O BRAnMD se confirma como uma alternativa de tratamento viável e capaz de remover patógenos.

\section{AGRADECIMENTOS}

Os autores agradecem ao Conselho Nacional de Desenvolvimento Científico e Tecnológico (CNPq) por conceder uma bolsa de mestrado em ciências a Juanne Nogueira Nascimento.

\section{CONTRIBUIÇÃO DOS AUTORES}

Conceitualização: Nascimento JN e Lopes WS; Metodologia: Nascimento JN, Santos RB, Cirne JRR, Lopes WS, Sousa JT, Leite VD; Redação - Primeira versão: Nascimento JN, Santos RB, Cirne JRR, Lopes WS, Sousa JT, Leite VD; Redação - Revisão \& Edição: Nascimento JN, Santos RB, Lopes WS; Supervisão: Nascimento JN.

\section{REFERÊNCIAS}

ALIBARDI, Luca et al. Anaerobic dynamic membrane bioreactor for wastewater treatment at ambient temperature. Chemical Engineering Journal, [s.l.], v. 284, p.130-138, jan. 2016. Elsevier BV. http://dx.doi.org/10.1016/j.cej.2015.08.111.

CAMPOS, C. M. M.; PEREIRA, L. E.; MOTERANI, F.; Efeitos do pH, acidez e alcalinidade na microbiopra de um reator anaeróbio de manta de lodo (UASB) tratando efluentes de suiocultura. Revista Ambiente \& Água - An Interdisciplinary Journal of Applied Science, v. 4, n.3, 2009.
DAGNEW, M.; PARKER, Q.; SETO, P. Anaerobic membrane bioreactors for treating waste activated sludge: Short term membrane fouling characterization and control tests. Journal of Membrane Science. n. 421-422, p.103-110, 2012.

ERSAHIN, Mustafa Evren et al. Applicability of dynamic membrane technology in anaerobic membrane bioreactors. Water Research, [s.l.], v. 48, jan. 2014. Elsevier BV. http://dx.doi.org/10.1016/j. watres.2013.09.054.

ERSAHIN, Mustafa Evren et al. Impact of anaerobic dynamic membrane bioreactor configuration on treatment and filterability performance. Journal of Membrane Science, [s.l.], v. 526, mar. 2017. Elsevier BV. http://dx.doi.org/10.1016/j. memsci.2016.12.057.

HERPIN, V. et al., Chemical effects on the soil-plant system in a secondary treated wastewater irrigated coffe platation - a pilot field study in Brazil. Agricultural Water Management, v. 89, n. 1, p. 105-115, 2007.

HIRAKAWA, C.; PIVELI, R.P.; SOBRINHO, P.A. Biofiltro aerado submerso aplicado ao pós-tratamento de efluente de reator UASB - estudo em escala piloto com esgoto sanitário. Revista de Engenharia Sanitária e Ambiental, v. 7, n. 1-2, p. 82-94, 2002.

HU, Y.; WANG, X. C.; HAO NGO, H.; SUN, Q.; YANG, Y. Anaerobic dynamic membrane bioreactor (AnDMBR) for wastewater treatment: A review, Bioresource Technology, v. 235, p 345-54, 2017.

KISO, Y.; JUNG, Y. J.; ICHINARI, T.; PARK, M.; KITAO, T.; NISHIMURA, K.; MIN, K.S. Wastewater treatment performance of a filtration bio-reactor equipped with a mesh as a filter material. Water Res., v.17, p. 4143-4150, 2000.

LI L,; XU G.; YU H.; XING J.; Dynamic membrane for micro-particle removal in wastewater treatment: Performance and influencing factors. Science of the Total Environment, 2018.

OMS - Organização Mundial da Saúde. Guidelines for the safe use of wastewater, excreta and greywater. Policy and regulatory aspects. WHO Library Cataloguing-in Publication Data, v.1, 2006.

SALEEM, M; ALIBARDI L; LAVAGNOLO M C; COSSU R; SPAGNI A. Effect of filtration flux on the development and operation of a dynamics membrane for anaerobic wastewater treatment. Journal of Environmental Management, v. 180, p. 459-465, 2016.

SMITH, A. L.; SKERLOS, S. J.; RASKIN, L. Pychrophilic anaerobic membrane bioreactor treatment of domestic wastewater. Water Res., v. 47 (4), p. 1655-1665, 2013.

SNIS, Sistema Nacional de Informações Sobre Saneamento. Ranking Do Saneamento Instituto Trata Brasil. São Paulo: Go Associados, 2019. Disponível em: <http://www.tratabrasil.org.br/ images/estudos/itb/ranking-2019/Relatório_-_Ranking_Trata_ Brasil_2019_v11_NOVO_1.pdf>. Acesso em: 1 dez. 2019. 
VERBYLA, M.E., OAKLEY, S.M., MIHELCIC, J.R., Wastewater infrastructure for small cities in an urbanizing world: integrating protection of human health and the environment with resource recovery and food security. Environ. Sci. Technol, V. 47, P. 3598e3605, 2013.

YU, Z., et al., Dynamic membrane bioreactor performance enhancement by powdered activated carbono addition:
Evaluation of sludge morphological, aggregative and microbial properties. Journal of environmental sciences, n. 11, 2018.

ZHANG, X.; WANG, Z.; WU, Z.; LU, F.; TONG, J.; ZANG, L. Formation of dynamic membrane in an anaerobic membrane bioreactor for municipal wastewater treatment, Chem. Eng. J., v. 165, p. 175183, 2010. 